\title{
Türkiye'de Kekik Olarak Kullanılan Bitkilerden Thymus capitatus (L.) Hoffm. et Link.
}

Thymus capitatus (L.) Hoffm. et Link, One of The Plants Used in Turkey as Thyme.

Nevin TANKER
Filiz İLIULU $\mathbf{U}^{*}$ *

\section{Gİ RISS}

Hastalıkların iyileştirilmesinde kullanılagelmekte olan bitkiler arasında kekik, hem halk ilâcı olarak bugün de kullanılması hem de birçok müstahzarın bileşimine girmesi nedeniyle önemini halâ korumaktasin

Tedavide kekiklerin içerdiği uçucu yağların ya da bu yağlardan izole edilen terpenik maddelerin (timol), antiseptik, antibakteriyel, antispazmodik, antiastmatik, ekspektoran ve funfusit etkilerinden yararlanılmaktadır (1-7). Ayrıca timol, bazı ilâç etken maddelerinin sentezinde başlangıç maddesi olarak tüketildikten başka antioksidan olarak dış hekimliğinde geçici dolgu yapımında, antiseptik banyo ve sabunların hazırlanmasında, bazı yiyeceklerin saklanmasında ve daha bir çok alanda kullanılmaktadır $(8,9,10,11)$.

Ülkemizde halk arasında hem baharat hem ilâç olarak kullanılan ve kekik adıyla bilinen bitkilerin bazıları araştırılmıştır. (12). Thymus türlerinin yanı sıra Labiatae familyasından diğer bazı bitkirin de. (Origanum heracleoticum L., Majorana oniles (L.) Benth., Satureja spicigera (C. Koch.) Boiss.) kekik olarak kullanıldığı saptanmıştır. $\mathrm{Bu}$ bitkilerin uçucu yağları üzerinde yapılan çalışmalar, bu uçucu yağların fenolik madde (timol, karvakrol) yönünden zengin olduğu-

Redaksiyona verildiği tarih: 30 Ocak 1981

* Ecz. Filiz İlisulu'nun "Thymus capitatus (L.) Hoffm. et Link Üzerinde Farmakognozik Araştırmalar" isimli doktora tezinin bitkinin tanıtılmasıyla ilgili kısmının özetidir. Sinav tarihi: Aralık 1980.

** Farmakognozi ve Farmasötik Botanik Kürsüsü, Eczacılık Fakültesi, Ankara Üniversitesi. 
nu ve Thymus vulgaris uçucu yağı yerine kullanılabileceğini göstermiştir (13). Kekik olarak kullanılan bitkiler üzerindeki bu çalışmalara karşın ülkemiz Thymus'ları üzerinde yapılmış araştırma sayısı azdır.

Türkiye'de 15 tanesi endemik olmak üzere 39 Thymus türünün varlığı saptanmıştır*. Tür sayısının çokluğuna karşın, morfolojik ve anatomik özelikleri incelenmiş, uçucu yağı ve diğer etken maddeleri (triterpenik maddeleri, flavonoitleri) araştırılmış tür olarak yalnızca

Thymus sipyleus Boiss. görülmektedir (14, 15).

Türkiye Thymus'ları içinde, halk arasında kullanımının yanı sıra her yıl İzmir çevresinde toplanıp diğer kekiklerle karıştırılarak dış ülkelere satıldığını saptadığımız Thymus capitatus (L.) Hoffm. et Link türünü, üzerinde çalışılacak ilk tür olarak ele aldık ve bitkinin tanınmasında yararı olacak morfolojik ve anatomik özeliklerini saptadık**.

\section{MATE RYAL}

İnceleme ve araştırmalarımızı yürüttüğümüz ve özelliklerini saptadı̆̆ımız materyal Datça-Çiftlik Yarımadasından İzmir Zeytinalan köyü ile Çanakkale Ezine ve Eceabat'tan toplanmıştır.

Bitkinin yayılışı: Thymus capitatus (L.) Hoffm. et Link literatürde

Thymbra capitata Griseb, Coridothymus capitatus (L.) Reichb fil.; Satureja capitata (L.) adlariyla da verilen bir Akdeniz bitkisidir (16, 17, 18, 19).

Bitkiye $600 \mathrm{~m}$ ye kadar olan yükseklerde, kumlu, kireçli yamaçlarda, maki açıklıklarında rastlanmaktadır. Herbaryum kayıtlarına göre bugüne değin Türkiye'de toplanmış örnekleri şunlardır:

1) $A_{1}$ ÇANAKKALE, Gelibolu (İSTE, 6091)

2) A1- ÇANAKKALE, Eceabat, Galata Ovası (İSTE, 20729)

3) $\mathrm{A}_{2}-$ BURSA, Gemlik Karacaali Köyü (AEF, 3064)

4) $B_{1}$ ÇANAKKALE, Ezine (AEF, 6650)

5) $\mathrm{B}_{1}$ İZMİR, Çeşme Çiftlik Köyü (İSTE, 15929)

*Hazirlanmakta olan "Flora of Turkey and East Aegean Islands" 7. cildinde Thymus' lar ile ilgili bölümü hazırlayan J. Jalas'ın notlarından alınmıştır.

** Bitkinin uçucu yağı üzerinde yapılan araştırma daha sonra yayınlanacaktır. 
6) B $_{1}$ - İZMİ R, Zeytinalan Köyü (AEF, 4976 AEF; 6333, 6334)

7) $\mathrm{B}_{1}$ - BALIKESİR, Burhaniye (J. Jalas 3489)*

Araştırmalarımız sırasında bunlara,

8) $\mathrm{C}_{1}$ - MUĞLA, Datça Çiftlik yarımadası (AEF 7031),

9) $B_{1}$ - İZMİR, Kuşadası (AEF, 7035)

10) A1- ÇANAKKALE, Eceabat (AEF, 6336) örnekleri ilâve edilmiştir.

\section{Bitkinin morfolojik özelikleri}

Bitki, 20-25 cm boyunda bazan daha yüksek olabilen bodur, dalları dik yastıkçıklar biçimindedir. Çok yıllık olan bitkinin gövde ve dallarının dip kısmı odunsudur. Gövde ve dallardan baharda çıkan yapraklar kış yaprakları adını alır. 4-10 $\mathrm{mm}$ boyunda sapsız, triagularlinear, tepesi akut, kenarları integer, hemen heen tüysüz, ancak tabanda siliat, damarlar belirsiz, çok sayıda ve uçucu yağ damlaları gibi görünen Labiatae tipi salgı tüyleri taşır. Kış yapraklarının koltuğundan çıkan yaz yaprakları demet halindedir (Şekil 1).

Çiçek durumu, oblong-konik başçık biçiminde, brakteler 6 × 2 $\mathrm{mm}$, imbrikat dizilişli, ovat veya lanseolat, yeşilimsi, kenarları siliat, çok sayıda salgı tüyü taşır. Brakteler $5 \mathrm{~mm}$ boyunda, yapraklara benzer. Kaliks kalıcı, 4-5 mm boyunda, sırttan yassılaşmış, 20-22 damar11, boğazı içte tüylü, 2 dudakl1, alt dudak 2 dişli, üst dudak alt dudaktan kısa 3 dişlidir (Şek. 1).

Korolla pembemsi-leylak ya da mavimsi-pembe renkli, $10 \mathrm{~mm}$ den uzun, 2 dudaklı, üst dudak 2 parçalı; çok sayıda salgı tüyü taşır, her 2 yüzü de tüylüdür. Stamenler 4 tane, korolladan uzun, filamentler tabanda korollaya yapışıktır. Anterler 2 tekalı, versatil. Ovaryum üst durumlu, 2 gözlü, stilus ginobazik, ince uzun pembemsimor renkli, korolla'dan dışarı çıkar, stigma bifit (Şekil 1).

Bitkiye baharın erken geldiği yıllarda hazirandan başlıyarak temmuz ağustos ve eylül ayları boyunca, çiçekli halde rastlanmaktadir.

* Bu örnekler, toplayan araştırıcıların özel numaralarıyla verilmiştir. "Flora of Tur key and East Aegean Islands" 7. cildinde bu bilgiler yayınlanmak üzeredir. 


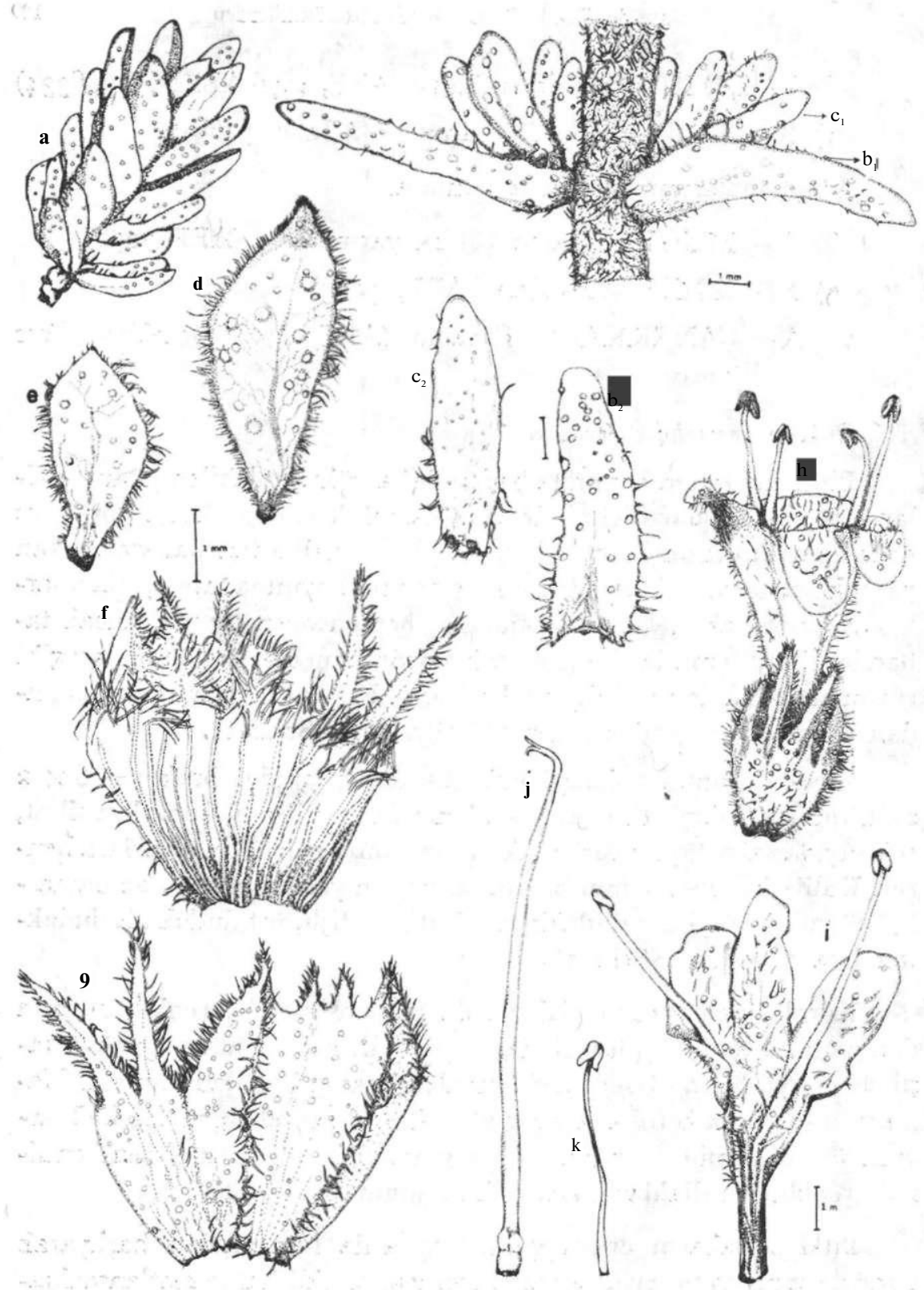

Şek. 1.. T. capitatus'da yeni sürgün (a), kış yaprakları $\left(b_{1}\right.$, b2) yaz yaprakları (c , $_{1}$ c2), brakte (d), brakteol (e), kaliks tüpünün açılmış haliyle içten (f) dıştan (g) ve tüm çiçeğin (h), korolla tüpünün açılmış haliyle içten (i) görünüşü ve pistil (j), stamen (k). 
Morfolojik özeliklerini özetlediğimiz $T$. capitatus, kaliks tüpünün sırttan düzleşmiş yassılaşmış ve 20-22 damarlı oluşuyla diğer Thymus türlerinden ayrilmaktadır (18).

Literatürde $T$. capitatus'a. Thymbra capitata adının da verildiğine işaret etmiştik. Ancak bu isimlendirmenin doğru olacağ 1 kuşkukuludur. Çünkü T. capitatus'da kaliks sırttan yassılaşmış 20-22 damarlı olduğu halde Thymbra cinsinde kaliks sırtta konveks ve 13 damarlıdır. Böyle bir yanılgıya düşülmesinin nedeni $T$. capitatus'un kaliksindeki sadece büyük damarların sayılmasıdır. Bu noktayı vurgulamak üzere $T$. capitatus ile Türkiye'deki Thymbra türü Thymbra spicata, çiçek durumu ve kaliks açısından karşılaştırılmıştır (Şek. 2).
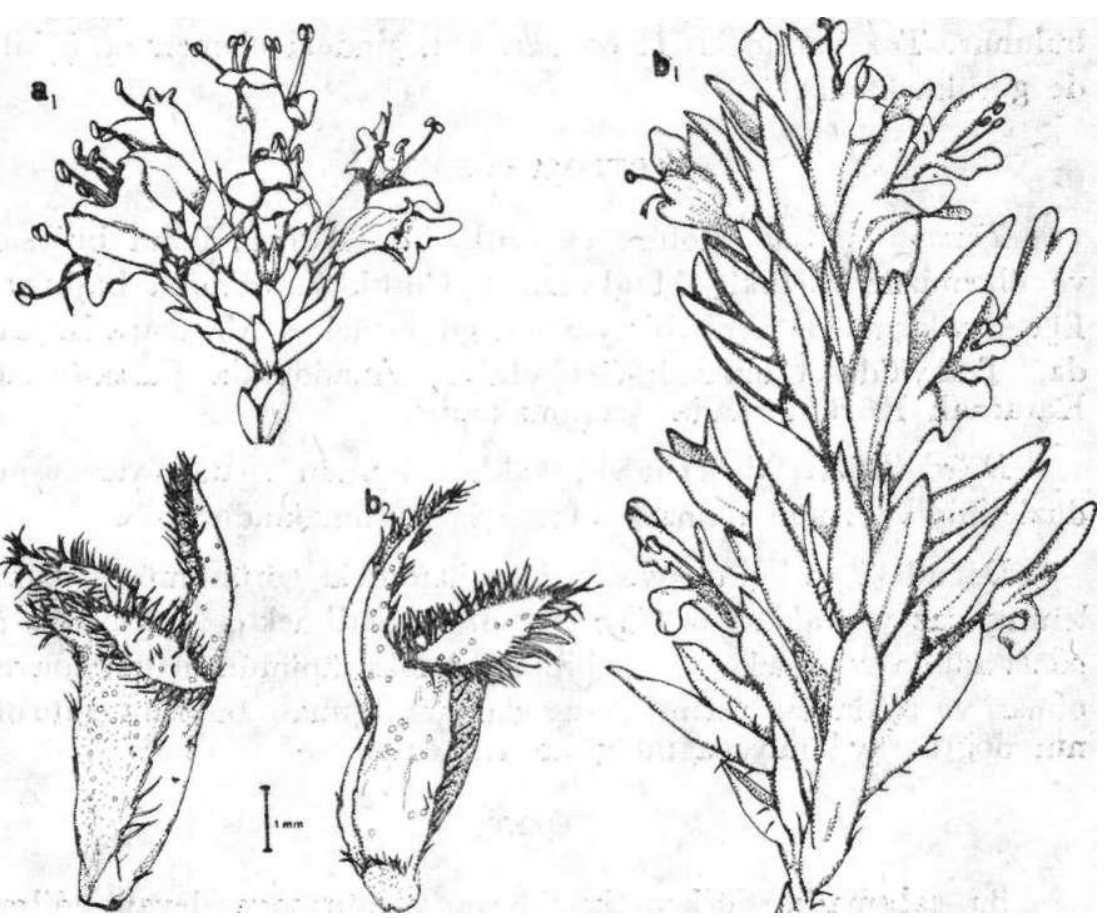

Şek. 2. Thymus capitatus (a) ile Thymbra spicata'nın (b) çiçek durumları (a1, b1) ve kaliks tüplerinin (a2, b2) karşılaştırılması. 
Yaprakların enine kesisinde, kalın bir mum tabakasının altında tek sıralı epiderma hücreleri ve epidermaya gömülmüş gibi görülen Labiatae tipi salgı tüyleri karakteristiktir* (Şek. 3).

Thymus cinsinde mezofil değişkenlik göstermekte ve bu nedenle yaprağın anatomik özeliklerinden, türlerin ayırımında güvenle yararlanılamamaktadır (20). T. capitatus yapraklarında da bu değişkenlik görülmektedir. Yaprağın tepe kısımlarında monofasiyal bir yapı vardır. Palizat çok sıralı ve sıktır. Yaprağın tabanına inildikçe, güneşaz gören kısımlarda palizat parenkima hücrelerinin seyrekleștiği ve gevşek bir doku oluşturduğu görülmektedir. Kıraç ve güneşli yamaçlardaki bitkilerde daha sık görülen bu değişim (21), Şekil 3 de gösterilmiştir.

Kekikler ticarette çoğu kez kaba veya ince toz edilmiş biçimde bulunur. Toz halindeki $T$. capitatus örneğindeki elementler Şekil 4 de görülmektedir.

TARTIŞMA ve SONUÇ

Thymus capitatus Hoffm. et Link, bir Akdeniz iklim bitkisidir ve ülkemizde özellikle Muğla-Datça Çiftlik Köyü'nden başlıyarak Ege Kıyılarımızda geniş bir yayılım göstermekte, Marmara Kıyısında, Trakya'da Çanakkale-Gelibolu'ya, Anadolu'da Bursa-Gemlik Karacaali Köyü'ne kadar uzanmaktadır.

Diğer Thymus türlerinden, kaliks tüpünün sırttan yassılaşmış, düzleşmiş ve 20-22 damarlı olmasıyla ayrılmaktadır.

Doğadaki yerleşimi, yastıkcıklar halindeki görünümü ve kümelenmiş yaz yapraklarıyla Thymbra sp. benzetilmekte ve Thymbra capitata adı da verilmekte ise de bitkinin kaliks tüpünün sırttan konveks olması ve 13 damar yerine 20-22 damar taşıması bu isimlendirmenin doğru sayılamıyacağını göstermektedir.

ÖZET

$\mathrm{Bu}$ çalışmada Türkiye kekiklerini araştırmaya devam edilmiş, halk arasında baharat ve ilâç olarak kullanılan, diğer kekiklerle karıştırılarak dış ülkelere satılan Thymus capitatus (L.) Hoffm. et Link

* Oil-dot adı verilen salgı tüylerinin renkleri ve sıklı̆̆ı bazı Thymus türlerinin tanısında ayırıcı özelik olarak kullanılmaktadır (19). 

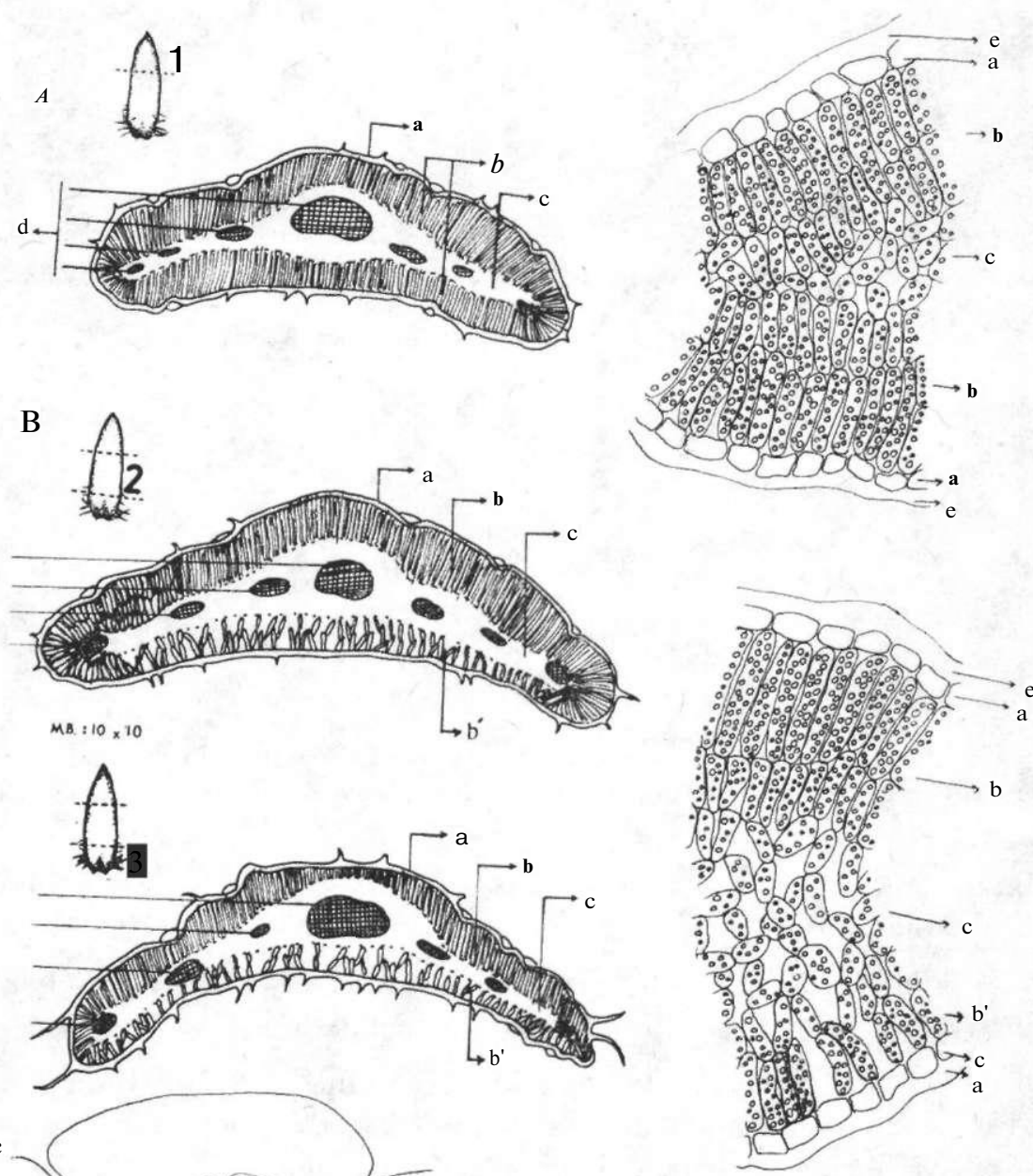

Şek. 3. Yaprak enine kesişinde monofasiyal yapı (1, A) ile değişiklikleri (2, 3, B) ve salgı tüyü (C) a- epiderma b- palizat parankiması b' seyrekleşmiş palizat c- sünger parenkiması d- iletim demeti e- mum tabakası f- sap hücresi g- salgı hücreleri. 


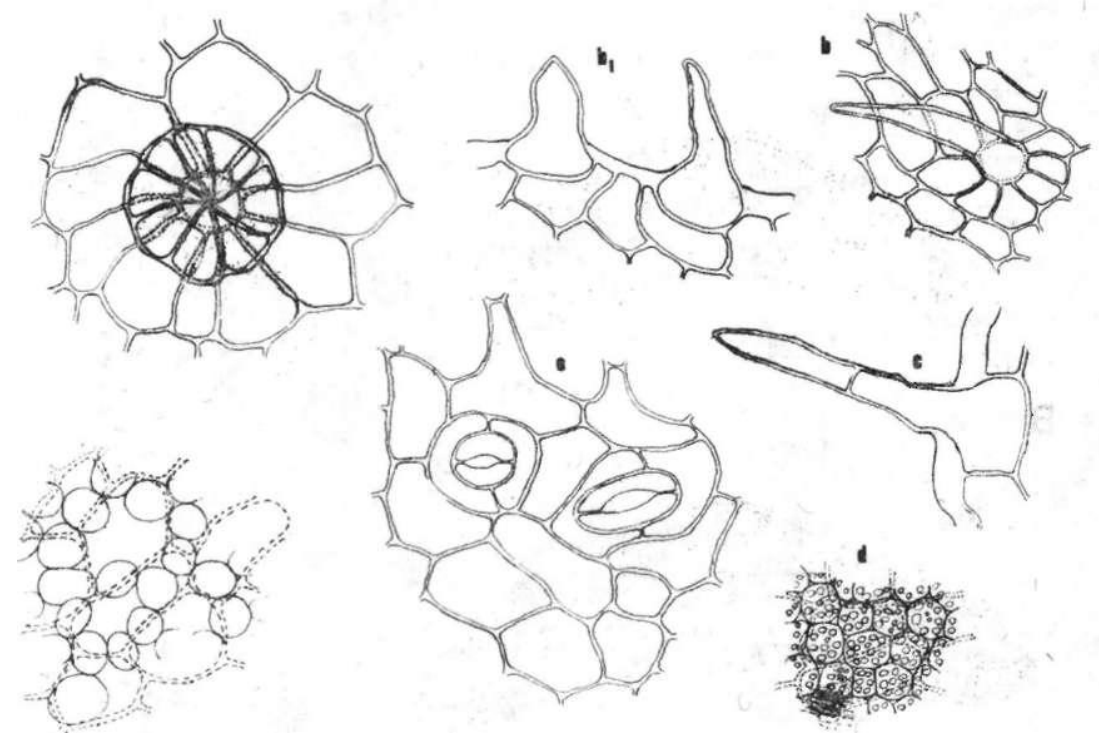

Şek. 4. T. capitatus yaprak tozunda görülen elementler a- salg1 tüyü, b1, b2 - tek hücreli örtü tüyleri c- a hücreli örtü tüyü d-palizat parankiması e- Stoma f- sünger parankiması.

bitkisi ele alınmış ve morfolojik-anatomik özelikleri ile yayılış alanları saptanmıştır.

Bitki, kaliks tüpünün sırttan yassılaşmış ve 20-22 damarlı olmasıyla diğer Thymus türlerinden ayrılmaktadır.

Thymbra spicata ile yapılan karşılaştırılmasında kaliksinin konveks ve 13 damarlı olmayışı nedeniyle Thymbra capitata şeklindeki isimlendirmenin doğru sayılamıyacağı saptanmıştır.

\section{S UMMARY}

This research has been carried out on Thymus capitatus (L.) Hoffm. et Link, one of the plants used as thyme in Turkey.

The morphological, and anatomical properties and the distribution of the plant has been determined.

This particular species is distinguished from other Thymus species by the dorsally flattened and 20-22 veined calyx tube. 
Literature scanning indicates that Thymus capitatus is sometimes reffered to as Thymbra capitata Griseb. In our research Thymbra sp. and Thymus capitatus have been compared and the differentiating ting morphological characters have been determined. The nomenclature Thymbra capitata Griseb. cannot be accepted.

\section{KAYNAKLAR}

1- Patakova, D., Chladek, M., Pharmazie 29 (11), 140-42, (1974).

2- Satoru, O., Intern. Symph. Food. Microbiol. 4 th Gatebourg Sweed 3-16 (1964)

3- Chırkına. N. N., Khort. T. P., Rast. Resur 4 (2), 186-89 (.1968). Ref.: C.A. Vol. 69, 99280.

4- Allegrini, J., Bollot. A., Prd. Probt Pharm. 29 (9), $817-19$ (1972).

5- Rochat, J., Bull. .ech. Gatlefosse SEPA 65, 62-7 (1970).

6- Michelin. N., Fr. Demande 2, 620 (1977) Ref.: C.A. Vol. 87, 17288 g.

7- Maruzella, C. J., Ligduri, L., J. Am. Pharm. Assoc. 47, 250-54 (1958).

8- Deleva, J. A., Ref.: C.A. Vol. 69, 61556 g.

9- Fujio, H., Hiyosch. A., Suminoe, K., Nippon Sho. Kogyo Gakkai, Shi. 16 (6), $341-46$ (1969)-

10 - Kasumov, F. Y., Ismailov, N. M., Izo. Akad. Nauk. Az. Ser: Biol. Nauk. 6, 26-31 (1976) C.A. Vol. 87,81244 d.

11 - Balg, E., Gstirner, F., Arch. Pharm. 2, 297 (1967).

12 - Gürgen, A. R., Atık. Tük. Zir. Enst. Der. 6, 301 (1946)

13 - Tanker, M., J. Fac. Pharm. Istanbul, 1, 32 (1965).

14- Tanker, N., J. Fac. Pharm. Ankara, 3, 115 (1973).

15-Çubukçu, A., Doktora tezi, H.Ü. Sağlık Bilimleri Fak. Ankara, (1976).

16- Boissier, E., Flora Orientaliş, Vol. IV, Genevae et Basileae (1979).

17 - Huxley, H., Taylor, W., Flowers of Greece and East Aegean, Chatto Windus, London (1977).

18- Post,. G., Dmsmore, E. J., Flora of Syria Palestine and Smai Vol. II, Am. Un. of. Beirut Pub.

19 - Heywood, V. H., Burges, N. A., Moore, D. M., Valentine, P. H., Walten, M., Tutin, T. G., Flora Europeae, Camb. Univ. Press. (1972).

20 - Metcalfe, C. J., Chalk, L., Anatomy of Dicotyledones, Oxford Univ. Press. London (1965).

21 - Harder, R., Schumachar, W., Firbas, F., Denffer, D. V., Strazburger's Textbook of Botany, Longmans, Green Co. Lt. (1965). 